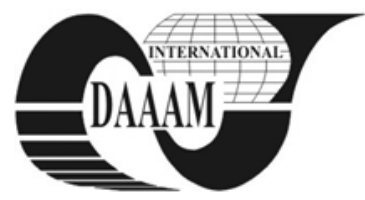

Annals of DAAAM for 2011 \& Proceedings of the 22nd International DAAAM Symposium, Volume 22, No. 1, ISSN 1726-9679 ISBN 978-3-901509-83-4, Editor B. Katalinic, Published by DAAAM International, Vienna, Austria, EU, 2011 Make Harmony between Technology and Nature, and Your Mind will Fly Free as a Bird Annals \& Proceedings of DAAAM International 2011

\title{
DETERMINATION OF OPTIMUM PARAMETERS FOR WELDING POLYMERIC FOILS USING THE HIGH-FREQUENCY TECHNIQUE
}

\author{
ROGALE, D[ubravko]; FIRST ROGALE, S[njezana] \& BOBOVCAN, M[artina]
}

\begin{abstract}
Intelligent article of clothing with adaptive microclimatic states is based on the sensor-computer system with the algorithm of intelligent behavior - actuator with micropneumatic elements, assigning it to intelligent systems of technical systems with artificial intelligence. It consists of several anthropometrically shaped and segmented thermoinsulative chambers interconnected with a mesh structure placed between the outer, top fabric and the lining constructed so that the chambers change their thickness and thermal insulation properties in proportion to the amount of inflated air. The chambers and welds must have necessary structural strength and air-tightness to meet the requirements of elasticity during wear, activation and deactivation of the chambers so that they can be welded using high-frequency $(H F)$ and ultrasonic techniques. This paper describes the method of welding airtight joints of segmented thermoinsulative chambers using the high-frequency technology, as well as the occurrence of undesirable extrusion of the edges of the weld and the method of determining the optimal parameters of $\mathrm{HF}$ welding with a minimum effect of the extrusion of the edges.

Key words: high-frequency welding, intelligent clothing, adaptive microclimatic states
\end{abstract}

\section{INTRODUCTION}

High-frequency welding machines are adapted for the specific technique used for welding artificial polymers according to the schematic in Fig.1. The material to be welded is placed between the electrodes connected to the highfrequency generator (Bajaj, 2001). The HF generator operates in such a way that heat is generated in the material to be welded between two electrodes, and as a result of the application of force $\mathrm{F}$ the materials are welded.

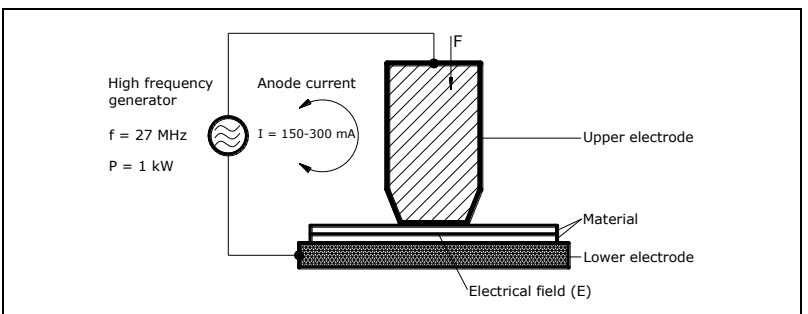

Fig. 1. Schematic drawing and parameters of HF welding

The reason for the generation of heat in the polymeric material is that the material to be welded consists of macromolecules with pronounced polarization so that some of its parts have pronounced electrical charges. Such molecules in an electric field polarize the direction of field forces. A change in the direction of field forces changes the position of the polarized molecule (Dixson \& Grewell, 2003). If a sufficiently rapid change of electric field is achieved, the orientation of molecules becomes fast enough to cause the appearance of heat dissipation within the material contained in a changing electric field.
However, such a phenomenon can be efficiently used in the high-frequency welding of garment parts made of synthetic polymers, so-called plastic foils (Firšt Rogale, at al 2009). For these purposes special parts of the high-frequency welding machines are used. HF oscillators which oscillate at a frequency $\mathrm{f}$ of about $27 \mathrm{MHz}$ and a power amplifier $\mathrm{P}$ up to $4 \mathrm{~kW}$, as well as high-frequency electrodes shaped to the contours of the seams of the clothing, Fig.1.

\section{MATERIALS AND EXPERIMENTAL PROCEDURE}

To make thermoinsulative chambers of the intelligent clothing with adaptive micro-climatic conditions, whose segment is shown in Fig.2, highly elastic polyurethane foil made by Bayer Epurex Films GmbH designated as Walopur 4201AU was used. It is characterized by material density of $1.15 \mathrm{~g} / \mathrm{cm}^{3}$, softening point of $140-150 \mathrm{C}^{0}$ and very high elongation at a breaking force of $550 \%$ (Firšt Rogale, at al 2010).

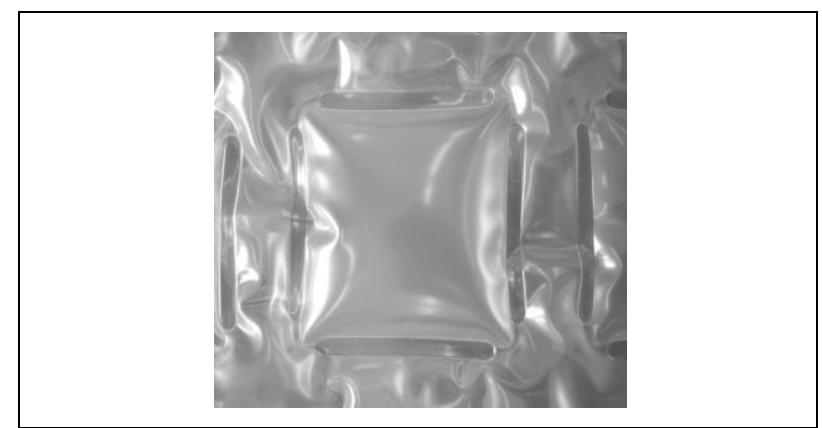

Fig. 2. Segment of the thermoinsulative chamber

In addition, the material has high UV resistance, hydrolytic stability, good thermal properties when using thermal and ultrasonic methods and good microbial resistance important for the integration into the clothing (Troughton, 2008). Thermoinsulative chambers can be welded using the ultrasonic and high-frequency welding technique, whereby the highfrequency technique exhibits better properties, because apart from welding the polymeric materials of which the chambers are made, other elements of the micro-pneumatic system can be welded, e.g. pipelines. In the feasibility prototype compressed air is blown through a pipe PUN-4X0.75-BL made by the Company FESTO. To activate the process of inflating compressed air into the thermoinsulative chambers solenoid valves made by Company FESTO of the series MicroPneumatic, designated MZH-3-M3-L-LED were used, while to obtain compressed air, the microprocessor made by American Company Clark designated DR-4X2PN was used.

The segments of ribbed thermoinsulative chambers, shown in Fig. 2, were welded using the high-frequency technology at the Laboratory for Process Parameters of the Department of Clothing Technology of the Faculty of Textile Technology. To 
weld segments, a high frequency oscillator, which oscillates at a frequency of $27.12 \mathrm{MHz}$, and a power amplifier up to $1 \mathrm{~kW}$ as well as a specially designed high frequency electrode shaped according to the weld whose footprint is shown in Fig. 2, were used. The thermoinsulative chamber of the garment with adaptive microclimatic conditions is placed between the highfrequency electrode and the grounded work surface of the machine, so the material to be welded behaves as a capacitor dielectric, and heat is generated over the whole volume of the material to be welded by connecting high-frequency voltage.

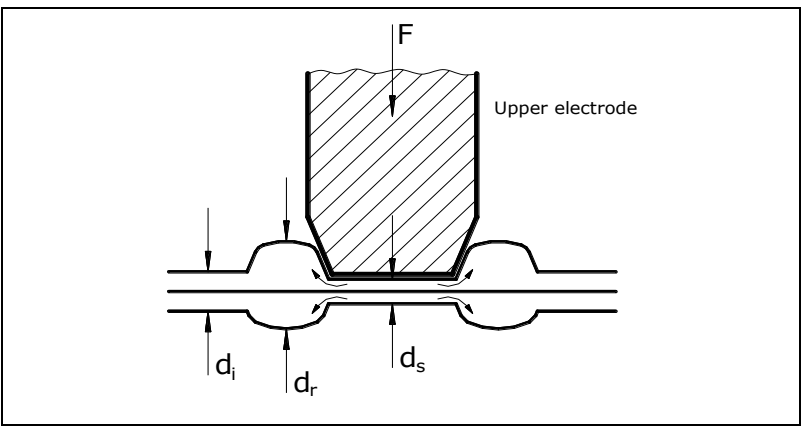

Fig. 3. Schematic of the extrusion of the edges during welding

The aim of this study was to determine the optimal parameters of fusing with HF technique in order to determine the optimum range of fusing with sufficient force, but with a minimum thickness.

Welding time was $7 \mathrm{~s}$, anode current (I) of $150 \mathrm{~mA}, 180$ $\mathrm{mA}, 200 \mathrm{~mA}, 240 \mathrm{~mA}, 260 \mathrm{~mA}, 300 \mathrm{~mA}$ changed with a constant anode voltage of $2700 \mathrm{~V}$. To measure the thickness of the weld $\left(d_{s}\right)$, the thickness of the extruded edges $\left(d_{r}\right)$ and the thickness of the workpiece $\left(\mathrm{d}_{\mathrm{i}}\right)$, Fig. 3, a micrometer made by Insize Company and a digital micrometer made by Toolcraft Company were used.

\section{RESULTS AND DISCUSION}

In the performed experiment the anode current was altered by high-frequency connection, and pressure force $(F)$ on the workpiece, anode voltage of the amplifier and welding time were kept constant. In these conditions weld thickness $\left(d_{s}\right)$ and thickness of the extruded edges $\left(d_{r}\right)$ were measured, Fig. 3. In doing so, following results were obtained by altering the thickness and the thickness of the circuit extruded edges and are shown in the diagram in Fig. 4. It is evident that the thickness of the weld is proportionally equal to the value of anode current up to $240 \mathrm{~mA}$, and then begins to assume lower values. At the same time an increase in the anode current enhances the thickness of the extruded edge, causing a negative effect on HF welding. The thickness of the extruded edge remains relatively small with a value of anode currents $150-240 \mathrm{~mA}$ and is approximately $10 \%$ of the initial thickness of the welded material. By increasing the current from $240 \mathrm{~mA}$ to $300 \mathrm{~mA}$ the thickness of the extruded edge rapidly grows to assume the practically double value of the initial thickness of the welded material. At the same, when the currents are the highest, the value of the weld thickness reduces to $60 \%$ of the value of the initial thickness of the welded material.

Reduction of the weld thickness is reflected in a reduction of the weld strength, which is technologically unacceptable. Likewise, too small anode current does not heat up the weld area sufficiently, and the weld strength is also not high enough. The found results lead to the conclusion that these tests can determine the optimum parameters of HF welding, and that they in this case range from the lower optimum limit of 180 $\mathrm{mA}$, whereby a welding power of $450 \mathrm{~W}$ was measured, to the upper optimum limit of $240 \mathrm{~mA}$ and welding power of approximately $650 \mathrm{~W}$.

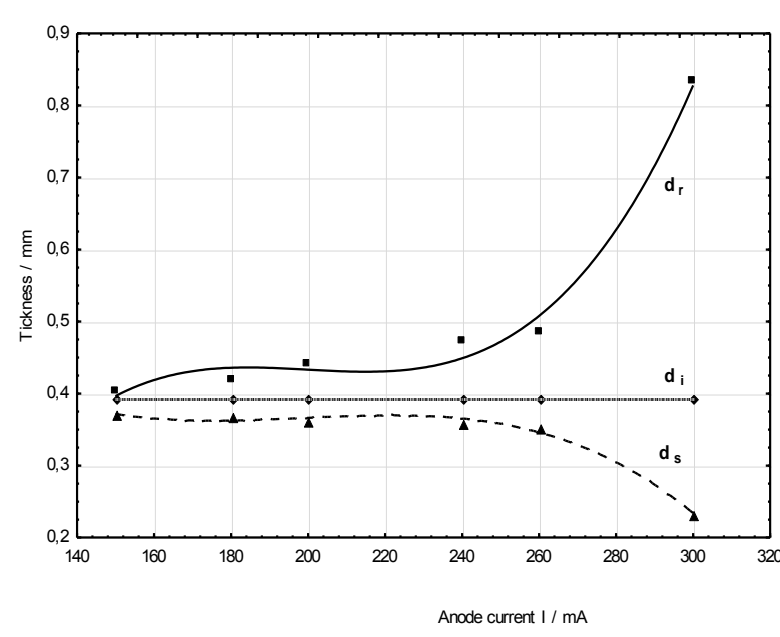

Fig. 4. Dependence of the workpiece thickness, weld thickness and thickness of the extruded edges on anode current

Lower power and welding currents result in a very poor weld, and when higher than the optimum they also result in a lower weld strength due to the reduced weld thickness and highly extruded and pronounced edges of their welding.

Future research will focus on determining the optimum parameters of ultrasonic welding in order to find the best method of fusing the thermoinsulative chamber.

\section{CONSLUSION}

The high-frequency welding technique has very good development possibilities for manufacturing thermoinsulative chambers of the intelligent clothing. This requires determining the lower and upper limit of optimal welding. Below the lower limit of the optimal welding there is no negative effect of extruded edges, but the welding power is too low to achieve sufficient weld strength.

Above the upper limit of optimal welding parameters too much power was supplied, which caused a very pronounced effect of extruded edges and a reduction of the weld thickness which was also reflected in a reduction of weld strength. It can also be concluded that the technological process of HF welding should be performed near the lower optimum limit because energy consumption in this area is the lowest, anode current is the lowest possible, which directly affects the resources of the high-frequency amplifier.

\section{REFERENCES}

Bajaj, P. (2001). Thermally sensitive materials, In: Smart fibers, fabric and clothing, Tao, X. (Ed.), 58- 82, Woodhead Publishing Ltd, ISBN 185573546 6, Abington

Dixson, J. P. \& Grewell, D. (2003). Radio Frequency Welding, In: Plastics and Composites Welding Handbook, Grewell, Benatar, Park, (Ed.), 249-270, Hanser, ISBN 1-56990-3131, Ohio

Firšt Rogale, S.; Rogale, D.; Dragčevic, Z. \& Nikolić, G. (2010). Controllable Ribbed Thermoinsulative Chamber of Continually Adjustable Thickness, Patent protection No. WO2009115851, World Intellectual Property Organization

Firšt, S., Runkas, M., Rogale D., Dragčević Z. \& Nikolić G.,\& Dragčević, Z. (2009). Microcontroller System for Temperature Measuring Inside Intelligent Clothing with Active Thermal Insulation, Proceedings of the 20th $D A A A M$, Katalinic, B. (Ed.), 143-144, Vienna, Austria, November 2009

Troughton, M. J. (2008). Handbook of plastics joining, William Andrew Inc. ISBN 978-0-8155-1581-4, Norwich 